\title{
The quality of reporting of randomised controlled trials in asthma: a systematic review
}

\author{
*Chara Ntala', Panagiota Birmpili', Allison Worth ${ }^{2}$, Niall H Anderson ${ }^{2}$, Aziz Sheikh,3 \\ University of Patras, Medical School, University Campus, PC 26504, Rio, Patras, Greece \\ ${ }^{2}$ Allergy and Respiratory Research Group, Centre for Population Health Sciences, The University of Edinburgh, Medical School, Edinburgh, UK \\ ${ }^{3}$ Division of General Internal Medicine and Primary Care, Brigham and Women's Hospital/Harvard Medical School, Boston, Massachusetts, \\ USA
}

Received 1st August 2013; revised 7th September 2013; accepted 12th September 2013; online18th November 2013

\begin{abstract}
Background: There are concerns about the reporting quality of asthma trials.

Aims: To describe the reporting of contemporary asthma trials and to identify factors associated with better reporting quality.

Methods: Two reviewers independently searched MEDLINE for randomised controlled trials (RCTs) of asthma published between January 2010 and July 2012 in leading generalist and specialist journals. We calculated the proportion of trials that adequately reported each Consolidated Standards of Reporting Trials (CONSORT) checklist item and an overall quality score for each trial. Factors associated with better reporting quality were investigated.

Results: Thirty-five RCTs satisfied our eligibility criteria. Four trials adequately reported $<50 \%$ of the items, 15 adequately reported $50-60 \%$ of items, and 16 adequately reported $>60 \%$ of items. Seventeen of the 38 CONSORT items were consistently well reported in more than two-thirds of the articles. In contrast, nine items were poorly reported in more than half the trials - namely, identification as a randomised trial in the title (40.0\%), an adequate structured summary/abstract (48.6\%), details of eligibility criteria (34.3\%), recruitment $(48.6 \%)$, randomisation procedures $(22.9 \%)$, intervention $(38.5 \%)$, harms $(34.3 \%)$, the funding source $(45.7 \%)$, and access to the full trial protocol $(17.1 \%)$. Studies led by teams in high-income country settings were associated with better quality of reporting (relative risk=1.33, 95\% Cl 1.09 to 1.64 ).

Conclusions: The quality of reporting in contemporary asthma literature remains suboptimal. We have identified important areas in which reporting quality needs to be improved.

(C) 2013 Primary Care Respiratory Society UK. All rights reserved.

C Ntala et al. Prim Care Respir J 2013; 22(4): 417-424

http://dx.doi.org/10.4104/pcrj.2013.00089
\end{abstract}

Keywords asthma, CONSORT statement, quality of reporting, randomised controlled trial, systematic review

See linked editorial by Been et al. on pg 388

The full version of this paper, with online appendix,

is available online at www.thepcrj.org

\section{Introduction}

The randomised controlled trial (RCT) is the most robust design for assessing the efficacy and effectiveness of treatments.' As a result, clinical decision-making has over decades been directed away from reliance based solely on the doctor's clinical experience towards a paradigm based on evidence derived from RCTs. The results of RCTs have subsequently been translated into guidelines containing evidence-graded recommendations which clinicians are encouraged to use as the basis of good clinical practice. ${ }^{2}$ If, however, the 'raw material' or trial is flawed, the conclusions cannot be trusted, hence the need to appraise critically the quality of the underpinning trial evidence. $^{3}$

Quality is a multidimensional concept which relates to the design, conduct, and analysis of a trial, its clinical relevance, and its reporting. ${ }^{3}$ In most cases the RCT report is the only source for clinicians, guideline developers, and other researchers to judge the validity and generalisability of the results, so the quality of reporting of trials is of inherent interest. ${ }^{4}$ It is then of considerable concern that

\footnotetext{
* Corresponding author: Dr Chara Ntala, Medical School University of Patras (Greece), Par. Synt. Zisi 99, P.C:26331, Patras, Greece.

Tel: +306987175000 E-mail: hara_da@hotmail.com
} 
the quality of reporting of RCTs is often suboptimal. ${ }^{5}$

In response to these concerns about the quality of reporting of RCTs, an international group developed in the mid-1990s the Consolidated Standards of Reporting Trials (CONSORT) Statement. ${ }^{6}$ This was first published in 1996 and then updated in 2001. ${ }^{5}$ After an expert meeting in January 2007 it was further revised, resulting in the latest iteration - the CONSORT 2010 Statement. ${ }^{5}$

The current CONSORT Statement (hereafter referred to as CONSORT) comprises a checklist of essential items that should be included in reports of RCTs and a diagram for documenting the flow of participants through a trial. It is formulated primarily for use with reports of two-arm parallel-group RCTs. Many of the CONSORT data fields are, however, also relevant to a wider spectrum of trial designs such as non-inferiority, equivalence, factorial, cluster, and crossover trials. ${ }^{5}$ Extensions to the CONSORT checklist for reporting trials with some of these other designs have been published, ${ }^{7-9}$ as have those for reporting particular types of data (i.e. harms ${ }^{10}$ ), types of interventions (i.e. non-pharmacological treatments ${ }^{11}$ and herbal interventions $\left.{ }^{12}\right)$, and abstracts. ${ }^{13}$ In this systematic review we have, where appropriate, used the non-pharmacological, non-inferiority and equivalence, cluster and pragmatic extensions of CONSORT.

CONSORT criteria have been used to assess the reporting quality of RCTs in several disease areas ${ }^{4,14,15}$ and journal types. ${ }^{16-18}$ Asthma is a serious public health problem throughout the world and therefore a substantial body of research is conducted annually. ${ }^{19}$ However, there have been no recent assessments of the quality of RCTs reported in the asthma literature. The only previous study on clinical trials of asthma treatments was undertaken for the period 1984-1997 and was published in 2002 in two reports. ${ }^{20,21}$ Initially this involved a comparison between RCTs published in Spanish and English language journals, ${ }^{21}$ which was then followed by a secondary analysis of a subsection of the same dataset focusing solely on the quality of RCTs in English. ${ }^{20}$ The first article showed poorer reporting quality of the RCTs in Spanish publications and a strong association between the type of journal, type of intervention, and the comparison measure used and reporting quality. Moreover, this study highlighted the necessity for better reporting in general in the asthma literature, leading authors to advocate the more widespread use of a checklist by authors and editors in order to improve reporting standards. ${ }^{21}$

Building on this earlier work, we examined the quality of reporting of asthma clinical RCTs in the contemporary asthma literature. Our secondary aim was to investigate if there is an association between specific trial characteristics that have previously been identified in the literature in influencing reporting quality and the actual quality of the trial reports. We hypothesised that trials published in general medicine journals with high impact factors (IF) conducted or led by teams in high-income countries with industrial funding, evaluating drug interventions, and having multiple participating centres were associated with better quality.

\section{Methods}

\section{Study selection}

We searched the electronic database MEDLINE (via Ovid) using
Table 1. Generalist and specialist journals and number of asthma trials identified

Publication journal RCTs included

\begin{tabular}{ll}
\hline General medicine & 6 \\
New England Journal of Medicine & 3 \\
\hline Lancet & 1 \\
\hline Journal of the American Medical Association & 1 \\
\hline Annals of Internal Medicine & 1 \\
\hline Public Library of Science Medicine & 0 \\
\hline British Medical Journal & 0 \\
\hline Archives of Internal Medicine & 0 \\
\hline Canadian Medical Association Journal & 0 \\
\hline BioMed Central Medicine & 0 \\
\hline Mayo Clinic Proceedings & 0 \\
\hline Specialty journals & 29 \\
\hline American Journal of Respiratory \& Critical Care Medicine & 6 \\
\hline Thorax & 2 \\
\hline European Respiratory Journal & 3 \\
\hline Chest & 5 \\
\hline Respiratory Research & 1 \\
\hline Pulmonary Pharmacology \& Therapeutics & 2 \\
\hline International Journal of Tuberculosis \& Lung Disease & 0 \\
\hline Pediatric Pulmonology & 0 \\
\hline Respiratory Medicine & 8 \\
\hline Respirology & 2 \\
\hline RCTrandomised controlled trial. & \\
\hline
\end{tabular}

the search terms of the Cochrane Airways Group Specialised Register for asthma and RCTs for the period from January 2010 to July 2012. We included studies published in the top $10 \mathrm{impact}$ factor journals in general medicine and respiratory specialty journals using the most recent available rankings at the time (i.e. 2011 rankings, Table 1), ${ }^{22}$ as long as they published clinical trials and included articles related to asthma. We included parallel or cluster design RCTs involving human subjects with asthma as the only condition being examined. The trials were evaluating the clinical effectiveness of a treatment, which was defined as having at least one clinical outcome, irrespective of whether this was a primary or secondary outcome. We excluded any condition not described strictly as asthma (e.g. recurrent wheezing), even when it was a broader term that included it. The complete search strategy and detailed inclusion/exclusion criteria were specified in advance and documented in a protocol. ${ }^{23}$

Searches were independently undertaken by two reviewers (CN and PB) with support from AW and AS. Both reviewers independently screened the titles and abstracts of all retrieved articles, unmasked to study details. Full-text copies of potentially relevant studies were obtained and assessed for inclusion. Any disagreements were resolved by discussion between the reviewers; if 
necessary AS and AW arbitrated. Any additional material of the reports included as appendices were also obtained from the journal website or were acquired from the authors.

\section{Data extraction}

Data were independently extracted by two reviewers (CN and PB) from the selected studies using an appropriate electronic customised data extraction form ${ }^{23}$ that was previously pilot-tested on seven randomly selected studies and refined accordingly. Disagreements were resolved through discussion with AS. The following data on the general characteristics of trials were extracted: journal name, journal type (general medicine or specialty), IF, country of the team that conducted or led the study according to the corresponding author in case of multiple centres (high-income, middle income, low-income) defined using World Bank Group definitions, ${ }^{24}$ funding source (solely industry, partly industry, non-industry, unknown), trial design (parallel or cluster), conceptual framework (superiority, non-inferiority, equivalence), type of intervention (drug or non-pharmacological), number of participating centres (multiple or single centre).

We used a modified 38-item CONSORT-based checklist consisting of all the CONSORT checklist items plus one additional item from the non-pharmacological treatments extension. ${ }^{23}$ We assessed the adequacy of reporting according to the CONSORT 2010 guidelines and its extensions. 5,8,9,11,12 Each item was characterised as 'yes' if it was clearly and adequately reported or 'no' if it was partially reported, unclear, or not reported at all. Each 'yes' answer received a score of 1 and each 'no' answer was scored as 0. The overall quality scoring of the trial was calculated as a proportion of the 'yes' rated applicable items (possible range 0-38 points). In addition, we scored the overall quality of reporting using key parameters of internal validity summarised in the Cochrane Risk of Bias (RoB) tool ${ }^{25}$ and categorised the studies into those at low to moderate risk of bias and those at high risk of bias.

\section{Data analysis}

We calculated the proportion of trials that clearly and adequately reported each CONSORT item with a 95\% confidence interval $(\mathrm{Cl})$. An overall quality score was also calculated for each trial as a percentage of all the adequately reported applicable items with a $95 \% \mathrm{Cl}$, which was used to inform a global assessment of the quality of reporting. The general characteristics data were presented as numbers and percentages with $95 \% \mathrm{Cl}$. For the $\mathrm{Cl}$ calculations we used the Wilson (recommended) method ${ }^{26}$ of Confidence Interval Analysis (CIA) software (Version 2.2.0), this being preferred to the more commonly used Normal approximation method to calculate $\mathrm{Cls}$ as it has more reliable behaviour with small samples (i.e. it avoids limits crossing 0 or 1 ).

We then tested the associations between the following study characteristics: type and IF of journal of publication, funding source, country of the study, type of intervention, and number of participating centres and the quality of RCT (measured by the RoB tool and categorising the trials as low versus moderate to high RoB). Fisher's exact test and the Mann-Whitney test for categorical and continuous data, respectively, were used to identify variables associated with studies with a low to moderate risk of bias using SPSS software (version 20). The IF was evaluated

\section{Figure 1. PRISMA flow chart}

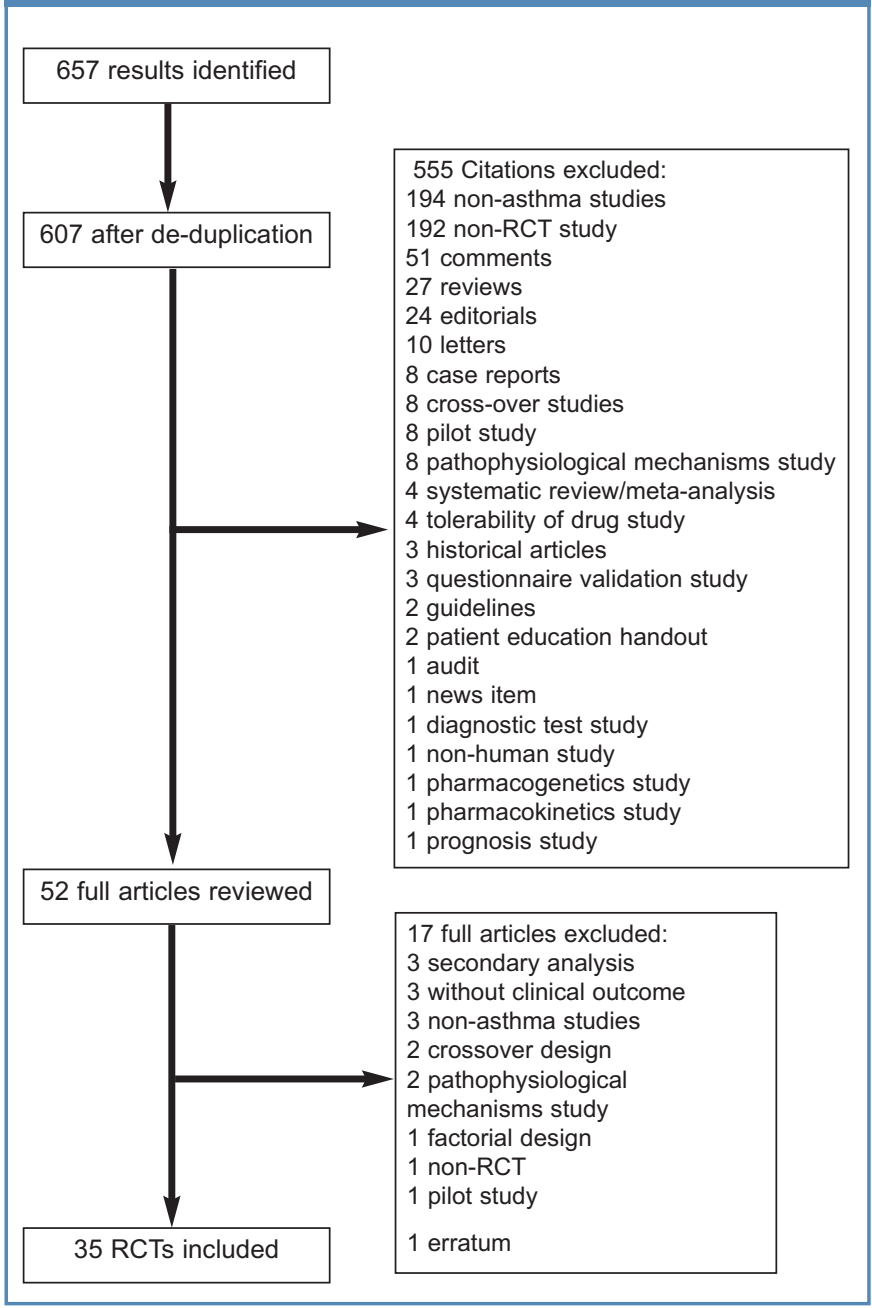

as the median difference between IF in the low to moderate RoB group of trials minus the IF in the high RoB group. This was run in MINITAB.

Further details of our methods are reported in the study protocol paper. ${ }^{23}$

\section{Results}

\section{Study characteristics}

Our searches identified a total of 657 citations, 607 of which remained after adjusting for duplicates. After screening the titles and abstracts, we examined 52 full-text study reports and identified 35 articles that met our inclusion criteria and comprised our study sample (see Figure 1, and Appendix 1 available online at www.thepcrj.org). The inter-rater $\kappa$ agreement for article selection was 0.64 . Table 2 shows the general characteristics of the trials. The majority of RCTs were published in specialty journal types, and the vast majority of the trials were conducted or led by investigators based in high-income countries. More than half of the RCTs were evaluating drugs, and the most frequent design and conceptual framework were parallel and superiority trials, respectively. Over half $(57.2 \%)$ of trials received industrial support. 


\begin{tabular}{|c|c|c|c|}
\hline General characteristic & $\begin{array}{l}\text { Number of } \\
\text { trials }(n=35)\end{array}$ & $\%$ & $95 \% \mathrm{Cl}$ \\
\hline \multicolumn{4}{|l|}{ Journal type } \\
\hline General & 6 & 17.1 & 8.1 to 32.7 \\
\hline Specialty & 29 & 82.9 & 67.3 to 91.9 \\
\hline \multicolumn{4}{|l|}{ Country of study } \\
\hline High income & 32 & 91.4 & 77.6 to 97.0 \\
\hline Upper middle income & 3 & 8.6 & 3.0 to 22.4 \\
\hline \multicolumn{4}{|l|}{ Funding source } \\
\hline Solely industry & 15 & 42.9 & 28.0 to 59.1 \\
\hline Partly industry & 5 & 14.3 & 6.3 to 29.4 \\
\hline Non-industry & 11 & 31.4 & 18.6 to 48.0 \\
\hline Unknown & 4 & 11.4 & 4.5 to 26.0 \\
\hline \multicolumn{4}{|l|}{ Type of intervention } \\
\hline Drug & 22 & 62.9 & 46.3 to 76.8 \\
\hline Non-pharmacological & 13 & 37.1 & 23.2 to 53.7 \\
\hline \multicolumn{4}{|l|}{ Number of centres } \\
\hline Multiple & 26 & 74.3 & 57.9 to 85.8 \\
\hline Single & 8 & 22.9 & 12.1 to 39.0 \\
\hline Unknown & 1 & 2.9 & 0.5 to 14.5 \\
\hline \multicolumn{4}{|l|}{ Trial design } \\
\hline Parallel & 33 & 94.3 & 81.4 to 98.4 \\
\hline Cluster & 2 & 5.7 & 1.6 to 18.6 \\
\hline \multicolumn{4}{|l|}{ Conceptual framework } \\
\hline Superiority & 30 & 85.7 & 70.6 to 93.7 \\
\hline Equivalence & 2 & 5.7 & 1.6 to 18.6 \\
\hline Non-inferiority & 3 & 8.6 & 3.0 to 22.4 \\
\hline
\end{tabular}

\section{Assessment of reporting quality}

Table 3 provides information on the reporting of each CONSORT item. Seventeen of the 38 CONSORT items we examined were consistently well reported in more than two-thirds of the articles; these included the scientific background, specific objectives, outcomes, statistical methods, participant flow, baseline data, numbers analysed, limitations, generalisability, interpretation, and trial registration. In contrast, the following nine items were poorly reported in more than half of the trials: identification as a randomised trial in the title, structured summary, eligibility criteria, implementation of randomisation, implementation of intervention, recruitment, harms, access to full trial protocol, and funding.

Table 4 presents an overall quality score for each trial as a global assessment of the quality of reporting. Four trials adequately reported $<50 \%$ of the items, 15 trials adequately reported $50-60 \%$ of items, and 16 adequately reported $>60 \%$ of items.

\section{Factors associated with better reporting quality}

We found that studies conducted or led by teams in high-income country settings were associated with better quality trials (Table 5). We did not identify any statistically significant associations between the other characteristics evaluated and the quality of trial reports (Table 5).

\section{Discussion}

\section{Main findings}

This work has found that the overall quality of reporting of contemporary asthma trials was suboptimal in the majority of cases. The reporting of each separate item varied significantly. Access to the full trial protocol was the least well reported item, present in only approximately one in five trials. The analysis of factors associated with better quality revealed a significant relationship between the studies that were conducted or led by teams in high-income country settings. Interpretation of findings in relation to previously published work

We identified certain trial parameters that were particularly inadequately reported, this finding being largely in common with previous reviews. The identification as a randomised trial in the title is very commonly omitted. ${ }^{17,27,28} \mathrm{~A}$ possible explanation for this could lie in the limitations on title length imposed by some journals and the related issue of restricting abbreviations (i.e. RCT) in the titles of papers. The presence of an adequately detailed structured summary/abstract was uncommon, but is generally variable in the literature. ${ }^{17,29}$ We did not use the CONSORT extension for abstracts, ${ }^{13}$ but nonetheless we believe that its rigorous enforcement by journal editors with a completed CONSORT abstract checklist requirement could help reduce this reporting deficit. The finding of poorly reported eligibility criteria is in contrast with what has been found in the literature, ${ }^{14,17,30}$ since the clinical features of the trials are usually better reported than the trial methodology and statistical features. ${ }^{14,31}$ This finding was principally due to the lack of reporting the methods of recruitment (which is subsumed under this heading), not the eligibility criteria. It may therefore be appropriate to adapt CONSORT in future iterations to encourage description of the method of recruitment as a separate item.

The implementation of randomisation also needs to be better reported, a finding in keeping with other reports. ${ }^{4,15,17,27}$ This finding may result from the perception that the clinical aspects of a trial are of greater importance than the methodology, which results in a deliberate or subconscious de-emphasis of data about the methodological aspects of RCTs. The description of nonpharmacological interventions also needs to be reported better. This limitation may have been partly due to the fact that we did not examine information published in previous abstracts, other publications, protocols, or contact authors for further information. It is common for non-pharmacological trials not to report fully all the details of an intervention, but the necessity for a complete reproducible description of the intervention and its implementation has been highlighted before. ${ }^{32}$ This key reporting element, which can otherwise take up a considerable proportion of the limited word count, could appear in electronic appendices of journal websites linked to the original publication.

The exact dates of recruitment and follow-up were also found to be poorly reported, in accordance with previous reviews. ${ }^{4,15}$ In an evaluation of safety reporting in randomised trials across seven different medical areas in 2001 it was noted that safety reporting was often inadequate and/or neglected. Key information that would take minimal space to report was often missing. ${ }^{33}$ According to our findings, the reporting of harms remains inadequate. We did not use the CONSORT extension for this item, but we suggest that authors should become more familiar with this CONSORT extension and 


\section{Table 3. Number and percentage with $95 \%$ confidence interval (Cl) of adequately reported items}

\begin{tabular}{|c|c|c|c|c|}
\hline Section/topic & Item no. & Checklist item & Trials $(n=35)$ & $95 \% \mathrm{Cl}$ \\
\hline \multirow[t]{2}{*}{ Title and abstract } & 1 & Identification as a randomised trial in the title & $14 / 35(40.0 \%)$ & 25.6 to 56.4 \\
\hline & 2 & Structured summary of trial design, methods, results, and conclusions & $17 / 35(48.6 \%)$ & 33.0 to 64.4 \\
\hline \multicolumn{5}{|l|}{ Introduction } \\
\hline \multirow[t]{2}{*}{ Background and objectives } & 3 & Scientific background and explanation of rationale & $31 / 35(88.6 \%)$ & 74.0 to 95.5 \\
\hline & 4 & Specific objectives or hypotheses & $26 / 35(74.3 \%)$ & 57.9 to 85.8 \\
\hline \multicolumn{5}{|l|}{ Methods } \\
\hline \multirow[t]{2}{*}{ Trial design } & 5 & Description of trial design (such as parallel, factorial) including allocation ratio & $22 / 35(62.9 \%)$ & 46.3 to 76.8 \\
\hline & 6 & $\begin{array}{l}\text { Important changes to methods after trial commencement (such as eligibility } \\
\text { criteria), with reasons }\end{array}$ & 0.0 & 0.0 \\
\hline \multirow[t]{2}{*}{ Participants } & 7 & Eligibility criteria for participants & $12 / 35(34.3 \%)$ & 20.8 to 50.8 \\
\hline & 8 & Settings and locations where data were collected & $18 / 35(51.4 \%)$ & 35.6 to 67.0 \\
\hline Interventions & 9 & $\begin{array}{l}\text { Interventions for each group with sufficient details to allow replication, } \\
\text { including how and when they were actually administered }\end{array}$ & $23 / 35(65.7 \%)$ & 49.2 to 79.2 \\
\hline \multirow[t]{2}{*}{ Outcomes } & 10 & $\begin{array}{l}\text { Completely defined pre-specified primary and secondary outcome measures, } \\
\text { including how and where they were assessed }\end{array}$ & $25 / 35(71.4 \%)$ & 54.9 to 83.7 \\
\hline & 11 & Any changes to trial outcomes after the trial commenced, with reasons & $1 / 1(100.0 \%)$ & 20.7 to 100 \\
\hline \multirow[t]{2}{*}{ Sample size } & 12 & How was sample size determined & $21 / 35(60.0 \%)$ & 43.6 to 74.4 \\
\hline & 13 & When applicable, explanation of any interim analyses and stopping guidelines & 0.0 & 0.0 \\
\hline \multicolumn{5}{|l|}{ Randomisation } \\
\hline \multirow[t]{2}{*}{ Sequence generation } & 14 & Method used to generate the random allocation sequence & $23 / 35(65.7 \%)$ & 49.2 to 79.2 \\
\hline & 15 & Type of randomisation; details of any restriction (such as blocking and block size) & $24 / 35(68.6 \%)$ & 52.0 to 81.4 \\
\hline $\begin{array}{l}\text { Allocation concealment } \\
\text { mechanism }\end{array}$ & 16 & $\begin{array}{l}\text { Mechanism used to implement the random allocation sequence (such as } \\
\text { sequentially numbered containers), describing any steps taken to conceal the } \\
\text { sequence until interventions were assigned }\end{array}$ & $21 / 35(60.0 \%)$ & 46.3 to 74.4 \\
\hline Implementation & 17 & $\begin{array}{l}\text { Who generated the random allocation sequence, who enrolled participants, } \\
\text { and who assigned participants to interventions }\end{array}$ & $8 / 35(22.9 \%)$ & 12.1 to 39.0 \\
\hline \multirow[t]{2}{*}{ Blinding } & 18 & $\begin{array}{l}\text { If done, who was blinded after assignment to interventions (e.g. participants, } \\
\text { care providers, those assessing outcomes) and how }\end{array}$ & $20 / 35(57.1 \%)$ & 40.9 to 72.0 \\
\hline & 19 & If relevant, description of the similarity of interventions & $13 / 24(54.2 \%)$ & 35.1 to 72.1 \\
\hline \multirow[t]{2}{*}{ Statistical methods } & 20 & Statistical methods used to compare groups for primary and secondary outcomes & $29 / 35(82.9 \%)$ & 67.3 to 91.9 \\
\hline & 21 & Methods for additional analyses, such as subgroup analyses and adjusted analyses & $22 / 24(91.7 \%)$ & 74.2 to 97.7 \\
\hline \multicolumn{5}{|l|}{ Results } \\
\hline \multirow[t]{2}{*}{ Participant flow } & 22 & $\begin{array}{l}\text { For each group, numbers of participants who were randomly assigned, received } \\
\text { intended treatment, and were analysed for the primary outcome }\end{array}$ & $29 / 35(82.9 \%)$ & 67.3 to 91.9 \\
\hline & 23 & For each group, losses and exclusions after randomisation, together with reasons & $27 / 35(77.1 \%)$ & 61.0 to 87.9 \\
\hline Implementation of interventions & 24 & Details of experimental treatment and comparator as they were implemented & $5 / 13(38.5 \%)$ & 17.7 to 64.5 \\
\hline \multirow[t]{2}{*}{ Recruitment } & 25 & Dates defining periods of recruitment and follow-up & $17 / 35(48.6 \%)$ & 33.0 to 64.4 \\
\hline & 26 & Why the trial ended or was stopped & 0.0 & 0.0 \\
\hline Baseline data & 27 & Table showing baseline demographic and clinical characteristics for each group & $28 / 35(80.0 \%)$ & 61.4 to 90.0 \\
\hline Numbers analysed & 28 & $\begin{array}{l}\text { For each group, number of participants (denominator) included in each analysis } \\
\text { and whether the analysis was by original assigned groups }\end{array}$ & $31 / 35(88.6 \%)$ & 74.0 to 95.5 \\
\hline \multirow[t]{2}{*}{ Outcomes and estimation } & 29 & $\begin{array}{l}\text { For each primary and secondary outcome, results for each group and the } \\
\text { estimated effect size and its precision (such as } 95 \% \mathrm{CI} \text { ) }\end{array}$ & $23 / 35(65.7 \%)$ & 49.2 to 79.2 \\
\hline & 30 & $\begin{array}{l}\text { For binary outcomes, presentation of both absolute and relative effect sizes } \\
\text { is recommended }\end{array}$ & $22 / 24(91.7 \%)$ & 74.2 to 97.7 \\
\hline Ancillary analyses & 31 & $\begin{array}{l}\text { Results of any other analyses performed, including subgroup analyses and } \\
\text { adjusted analyses, distinguishing pre-specified from exploratory }\end{array}$ & $26 / 29(89.7 \%)$ & 73.6 to 94.6 \\
\hline Harms & 32 & All important harms or unintended effects in each group & $12 / 35(34.3 \%)$ & 20.8 to 50.8 \\
\hline \multicolumn{5}{|l|}{ Discussion } \\
\hline Limitations & 33 & $\begin{array}{l}\text { Trial limitations, addressing sources of potential bias, imprecision and, if relevant, } \\
\text { multiplicity of analyses }\end{array}$ & $24 / 35(68.6 \%)$ & 52.0 to 81.4 \\
\hline Generalisability & 34 & Generalisability (external validity, applicability) of trial findings & $28 / 35(80.0 \%)$ & 64.1 to 90.0 \\
\hline Interpretation & 35 & $\begin{array}{l}\text { Interpretation consistent with results, balancing benefits and harms, and considering } \\
\text { other relevant evidence }\end{array}$ & $35 / 35(100.0 \%)$ & 90.1 to 100.0 \\
\hline \multicolumn{5}{|l|}{ Other information } \\
\hline Registration & 36 & Registration number and name of trial registry & $24 / 35(68.6 \%)$ & 52.0 to 81.4 \\
\hline Protocol & 37 & Where full trial protocol can be accessed, if available & $6 / 35(17.1 \%)$ & 8.1 to 32.7 \\
\hline Funding & 38 & Sources of funding and other support (such as supply of drugs), role of funders & $16 / 35(45.7 \%)$ & 30.5 to 61.8 \\
\hline
\end{tabular}




\begin{tabular}{|c|c|c|}
\hline Trials & $\begin{array}{l}\text { Adequately } \\
\text { reported items* }\end{array}$ & $95 \% \mathrm{Cl}$ \\
\hline Aubier et al. (2010) & $19 / 32(59.4 \%)$ & 42.3 to 74.5 \\
\hline Baraket et al. (2012) & $12 / 31(38.7 \%)$ & 23.7 to 56.2 \\
\hline Bateman et al. (2012) & $27 / 32(84.4 \%)$ & 68.2 to 93.1 \\
\hline Bodzenta-Lukaszyk et al. (2011) & $19 / 33(57.6 \%)$ & 40.8 to 72.8 \\
\hline Bruzzese et al. (2011) & $19 / 32(59.4 \%)$ & 42.3 to 74.5 \\
\hline Busse et al. (2011) & $27 / 33(81.8 \%)$ & 65.6 to 91.4 \\
\hline Castro et al. (2011) & $25 / 33(75.8 \%)$ & 59.0 to 87.2 \\
\hline Castro et al. (2010) & $16 / 31(51.6 \%)$ & 34.8 to 68.0 \\
\hline Chanez et al. (2010) & $17 / 33(51.5 \%)$ & 35.2 to 67.5 \\
\hline Corren et al. (2011) & $28 / 33(84.8 \%)$ & 69.1 to 93.3 \\
\hline Dahl et al. (2010) & $19 / 31(61.3 \%)$ & 43.8 to 76.3 \\
\hline Deschildre et al. (2012) & $17 / 32(53.1 \%)$ & 36.4 to 69.1 \\
\hline Djukanovic et al. (2010) & $17 / 31(54.8 \%)$ & 37.8 to 70.8 \\
\hline Ducharme et al. (2011) & $29 / 35(82.9 \%)$ & 67.3 to 91.9 \\
\hline Fleming et al. (2012) & $21 / 32(65.6 \%)$ & 48.3 to 79.6 \\
\hline Gallegos-Solorzano et al. (2010) & $19 / 33(57.6 \%)$ & 40.8 to 72.8 \\
\hline Hanania et al. (2011) & $27 / 33(81.8 \%)$ & 65.6 to 91.4 \\
\hline Hashimoto et al. (2011) & $25 / 32(78.1 \%)$ & 62.1 to 89.0 \\
\hline Holbrook et al. (2012) & $27 / 33(81.8 \%)$ & 65.6 to 91.4 \\
\hline Hozawa et al. (2011) & $16 / 31(51.6 \%)$ & 34.8 to 68.0 \\
\hline Janson et al. (2010) & $14 / 34(41.2 \%)$ & 26.4 to 57.8 \\
\hline Kurashima et al. (2011) & $12 / 31(38.7 \%)$ & 23.7 to 56.2 \\
\hline Lipworth et al. (2012) & $18 / 31(58.1 \%)$ & 40.8 to 73.6 \\
\hline Meltzer et al. (2012) & $18 / 31(58.1 \%)$ & 40.8 to 73.6 \\
\hline Mendes et al. (2010) & $17 / 34(50.0 \%)$ & 34.1 to 65.9 \\
\hline Oei et al. (2011) & $15 / 33(45.5 \%)$ & 29.8 to 62.0 \\
\hline Pedersen et al. (2010) & 23/32 (71.9\%) & 54.6 to 84.4 \\
\hline Postma et al. (2011) & $17 / 33(51.5 \%)$ & 35.2 to 67.5 \\
\hline Powell et al. (2011) & $26 / 33(78.8 \%)$ & 62.2 to 89.3 \\
\hline Price et al. (2011) & $29 / 32(90.6 \%)$ & 75.8 to 96.8 \\
\hline Reddel et al. (2010) & $21 / 32(65.6 \%)$ & 48.3 to 79.7 \\
\hline Renzi et al. (2010) & $18 / 31(58.1 \%)$ & 40.8 to 73.6 \\
\hline Vaessen-Verberne et al. (2010) & $25 / 33(75.8 \%)$ & 59.0 to 87.2 \\
\hline Wilson et al. (2011) & $19 / 32(59.4 \%)$ & 42.3 to 74.5 \\
\hline Wilson et al. (2010) & $25 / 32(78.1 \%)$ & 61.2 to 89.0 \\
\hline
\end{tabular}

*The denominators vary since not all the CONSORT items were applicable in every study, so the maximum quality score differs between trials.

See Appendix 1, available online at www.thepcrj.org, for the full reference list

follow its recommendations. ${ }^{10}$

Protocols still serve as a detailed guide for a wide audience to research in progress and may help contribute to reduced duplication of effort by others who are planning to do similar research. They also minimise the likelihood of reviewers introducing bias into their
Table 5. Relative risks (RR) and 95\% confidence interval (CI) of low to moderate risk of bias (RoB)/good quality trials

\begin{tabular}{lll} 
Factor of interest & $\begin{array}{l}\text { RR/effect } \\
\text { estimate* }\end{array}$ & $95 \% \mathrm{Cl}$ \\
\hline Journal type (general vs. specialty) & 0.93 & 0.60 to 1.37 \\
\hline $\begin{array}{l}\text { Country (high income vs. upper } \\
\text { middle income) }\end{array}$ & 1.33 & 1.09 to 1.64 \\
\hline $\begin{array}{l}\text { Funding source (sole/part vs. } \\
\text { non-industry) }\end{array}$ & 1.16 & 0.78 to 1.75 \\
\hline $\begin{array}{l}\text { Intervention (drug vs. } \\
\text { non-pharmacological) }\end{array}$ & 1.16 & 0.82 to 1.64 \\
\hline Centres (single vs. multiple) & 0.83 & 0.59 to 1.19 \\
\hline Impact factor (IF) & -0.32 & -5.65 to 4.24 \\
\hline $\begin{array}{l}\text { *All factors of interest are calculated as RR except the IF which is } \\
\text { the median difference between IF in low to moderate RoB group } \\
\text { minus the IF in the high RoB group. }\end{array}$ &
\end{tabular}

review by making major changes that might otherwise remain undisclosed and undetectable. The publication and access to both protocols and completed reviews allows the tracking of any changes that have taken place and an examination of what effect this may have had on the results of the review. ${ }^{34}$ Unfortunately, from our findings, access to the full trial protocol is still limited. Other reviews have also noted similar findings s $^{27,28}$ and, in fact, one did not identify a single RCT with access to the protocol. ${ }^{17}$ This may be partly explained by the previously limited opportunity to include online material with the manuscript or the previous availability of a journal for protocol publication. Nowadays such journals are available; in fact, some require access to the full study protocol for the submission of an RCT. On the downside, they are primarily open access and may be expensive, especially for researchers in low- and middle-income country settings.

Finally, the suboptimal reporting of sources of funding is also a finding that is common to other similar reviews. ${ }^{28}$ This is important since full financial disclosure reduces the suspicion that something of relevance to objectivity is being hidden and allows readers to form their own opinions on whether a conflict of interest exists and what relevance that has to the study. ${ }^{35}$ Journals should be more specific in their instructions to authors on the types of financial associations related to their submission that warrant disclosure. ${ }^{35}$

In contrast, 13 items in our study seem to have a high level of compliance; more than $70 \%$ of the trials have adequately reported certain items, including issues relating to internal validity (participant flow and numbers analysed) and external validity (interventions, definition of outcome measures and baseline data).

We encountered a lot of discrepancies in evaluating the limitations section of the discussion so we needed a way to operationalise this. If we did not identify possible bias according to the RoB tool, we considered that sources of potential bias were not present. In other reviews the discussion items were excluded as they were considered too subjective to evaluate. ${ }^{16,30}$

\section{Strengths and limitations of this study}

Our study has certain strengths. It is the only contemporary evaluation 
on the quality of reporting of RCTs in asthma and was undertaken following development and publication of a detailed protocol. The selection and extraction processes were independently undertaken by two reviewers with a robust strategy to solve disagreements between reviewers. Analysis involved the testing of a priori clearly stated hypotheses.

It also has several potential limitations. We used the CONSORT checklist to assess the quality of reporting and, in doing so, we weighted all items equally, although the relative importance of each might be different. In the absence of any suitable alternative validated quality assessment instrument, ${ }^{1}$ we used the RoB tool in order to measure the quality of the RCT and to investigate our secondary hypotheses. However, in these evaluations we did not measure the RCT methodological quality directly because we did not verify the information from the authors or their protocols. One observational study found that 52 of 54 trials with unclear allocation concealment in the trial publication were adequately concealed according to a pre-announced telephone interview of the investigators. $^{36}$ Thus, when authors of RCTs do not report concealment and blinding, this does not necessarily mean that the studies were unconcealed. ${ }^{36}$ However, two observational studies that compared the content of study reports with the design features described in the protocols of RCTs had contradictory findings. One study found that many trials with unclear allocation concealment in the article also had an unclear description in the protocol. ${ }^{37}$ The other concluded that the reporting of methodological aspects of RCTs does not necessarily reflect the conduct of the trial, identifying the use of methodological safeguards despite not explicitly reporting them. ${ }^{38}$ Therefore, the quality of reporting can be taken only as an imperfect surrogate of true methodological quality. ${ }^{39}$ Nevertheless, because the report is usually the only source for clinicians and other researchers to judge the validity and generalisability of the results, the quality of the report has an important value by itself. In addition, poor reporting of $\mathrm{RCT}$ findings can result in overestimation of treatment effect and may potentially lead to erroneous conclusions. ${ }^{40,41}$

Our study sample was small and this may have contributed to our inability to identify some potentially important predictors of the quality of trial reporting. This is due to the limited time period that we covered, the restriction to trials published in only 20 high IF journals, and the strict definition of asthma that we used (excluding broader conditions that might include it such as recurrent wheezing). These restrictions may also affect the generalisability of our results to the rest of the literature on asthma. In addition, our study selection exclusively from top journals may overestimate the quality of asthma $\mathrm{RCTs}$ in general. The small study sample along with the small number of low RoB studies (two low RoB studies, nine moderate RoB studies, and 27 high RoB studies) forced us to combine low with moderate RoB studies even though this is not recommended. ${ }^{25}$ This represented a deviation from our original plan. ${ }^{23}$

Other reviews have identified the following factors associated with better quality: the time of publication, involvement of a methodologist/epidemiologist in a study, endorsement of CONSORT by the journal in which the study is published, size of the trial, and positive trial outcomes. ${ }^{4,14,16}$ Testing these additional hypotheses was, however, beyond the scope of this study. The exclusion of crossover and factorial designs trials is also a limitation. We made this decision because the 2010 CONSORT Statement is only intended for RCTs with a parallel-group design ${ }^{5}$ and so far there is only an extension for cluster trials. $^{8}$

\section{Implications for future research}

Given the persistent problems with suboptimal reporting, it will be important in due course to take a further look at asthma trial data to see if improvements have been made. It would also be helpful to study whether more uniform implementation of CONSORT by journal editors can help improve the quality of reporting of this literature. Finally, future studies that aim to study factors associated with better quality need to draw on our data, which can be used to inform sample size deliberations about the volume of literature that needs to be investigated.

\section{Conclusions}

Our results suggest that the quality of reporting in the contemporary literature on asthma remains suboptimal. We have identified deficiencies in reporting specific areas that need to be improved. All of the CONSORT items that we examined were adequately described in at least one article, which indicates that improved reporting is certainly possible. Improved awareness of the CONSORT statement by researchers, reviewers, and journal editors is likely to improve reporting quality.

\section{Handling editor Mike Thomas Statistical review Gopal Netuveli}

Conflicts of interest The authors declare that they have no conflicts of interest in relation to this article. AS is Joint Editor-in-Chief of the PCRJ, but was not involved in the editorial review of, nor the decision to publish, this article

Contributorship Study concept and design: AS. Acquisition, extraction, interpretation, and analysis of data: CN, PB. Statistical expertise: NA. Writing the manuscript: CN. Critical revision of the manuscript for important intellectual content: AS, AW. Study supervision: AS. AS is the guarantor

Funding CN's Erasmus LLP placement with The University of Edinburgh's Allergy and Respiratory Research Group was supported by the Erasmus-European Commission. AS is supported by The Commonwealth Fund, a private independent foundation based in New York City. The views presented here are those of the author and not necessarily those of The Commonwealth Fund, its directors, officers, or staff.

\section{References}

1. Moher D, Jadad AR, Nichol G, Penman M, Tugwell P, Walsh S. Assessing the quality of randomized controlled trials: an annotated bibliography of scales and checklists. Control Clin Trials 1995;16(1):62-73. http://dx.doi.org/10.1016/0197-2456(94)00031-W

2. Travers J, Marsh S, Williams M, et al. External validity of randomised controlled trials in asthma: to whom do the results of the trials apply? Thorax 2007;62(3):219-23. http://dx.doi.org/10.1136/thx.2006.066837

3. Juni $P$, Altman DG, Egger M. Systematic reviews in health care: assessing the quality of controlled clinical trials. BMJ 2001;323(7303):42-6. http://dx.doi.org/10.1136/bmj.323.7303.42

4. Rios LP, Odueyungbo A, Moitri MO, Rahman MO, Thabane L. Quality of reporting of randomized controlled trials in general endocrinology literature. J Clin Endocrinol Metab 2008;93(10):3810-16. http://dx.doi.org/10.1210/jc.2008-0817

5. Moher D, Hopewell S, Schulz KF, et al. CONSORT 2010 explanation and elaboration: updated guidelines for reporting parallel group randomised trials. Int J Surg 2012;10(1):28-55. http://dx.doi.org/10.1016/j.jijsu.2011.10.001

6. Begg C, Cho M, Eastwood S, et al. Improving the quality of reporting of randomized controlled trials. The CONSORT statement. JAMA 1996;276(8):637-9. 
http://dx.doi.org/10.1001/jama.276.8.637

7. Piaggio G, Elbourne DR, Altman DG, Pocock SJ, Evans SJ. Reporting of noninferiority and equivalence randomized trials: an extension of the CONSORT statement. JAMA 2006;295(10):1152-60. http://dx.doi.org/10.1001/jama.295.10.1152

8. Campbell MK, Elbourne DR, Altman DG. CONSORT statement: extension to cluster randomised trials. BMJ 2004;328(7441):702-08.

http://dx.doi.org/10.1136/bmj.328.7441.702

9. Zwarenstein M, Treweek S, Gagnier JJ, et al. Improving the reporting of pragmatic trials: an extension of the CONSORT statement. BMJ 2008;337:a2390. http://dx.doi.org/10.1136/bmj.a2390

10. Ioannidis JP, Evans SJ, Gotzsche PC, et al. Better reporting of harms in randomized trials: an extension of the CONSORT statement. Ann Intern Med 2004;141(10):7818. http://dx.doi.org/10.7326/0003-4819-141-10-200411160-00009

11. Boutron I, Moher D, Altman DG, Schulz KF, Ravaud P. Extending the CONSORT statement to randomized trials of nonpharmacologic treatment: explanation and elaboration. Ann Intern Med 2008;148(4):295-309. http://dx.doi.org/10.7326/0003-4819-148-4-200802190-00008

12. Gagnier JJ, Boon H, Rochon P, Moher D, Barnes J, Bombardier C. Reporting randomized, controlled trials of herbal interventions: an elaborated CONSORT statement. Ann Intern Med 2006;144(5):364-7. http://dx.doi.org/10.7326/0003-4819-144-5-200603070-00013

13. Hopewell $S$, Clarke $M$, Moher $D$, et al. CONSORT for reporting randomized controlled trials in journal and conference abstracts: explanation and elaboration. PLoS Med 2008;5(1):e20. http://dx.doi.org/10.1371/journal.pmed.0050020

14. Lai R, Chu R, Fraumeni M, Thabane L. Quality of randomized controlled trials reporting in the primary treatment of brain tumors. J Clin Oncol 2006;24(7):113644. http://dx.doi.org/10.1200/JCO.2005.03.1179

15. Anttila H, Malmivaara A, Kunz R, Autti-Ramo I, Makela M. Quality of reporting of randomized, controlled trials in cerebral palsy. Pediatrics 2006;117(6):2222-30. http://dx.doi.org/10.1542/peds.2005-1630

16. Bhandari M, Richards RR, Sprague S, Schemitsch EH. The quality of reporting of randomized trials in the Journal of Bone and Joint Surgery from 1988 through 2000. J Bone Joint Surg Am 2002;84-A(3):388-96.

17. Nojomi M, Ramezani M, Ghafari-Anvar A. Quality of reports on randomized controlled trials published in Iranian journals: application of the new version of consolidated standards of reporting trials (CONSORT). Arch Iran Med 2013; 16(1):20-2. doi: 013161/AIM.007.

18. DeMauro SB, Giaccone A, Kirpalani H, Schmidt B. Quality of reporting of neonatal and infant trials in high-impact journals. Pediatrics 2011;128(3):e639-44. http://dx.doi.org/10.1542/peds.2011-0377

19. Global Strategy for Asthma Management and Prevention GlfAG. Available from: http://www.ginasthma.org/.

20. Quinones D, Llorca J, Dierssen T, Delgado-Rodriguez M. Quality of published clinical trials on asthma. J Asthma 2003;40(6):709-19. http://dx.doi.org/10.1081/JAS-120023494

21. Quinones D, Llorca J, Prieto-Salceda D, Delgado-Rodriguez M. [Quality of clinical trials published in Spain on asthma in comparison to trials in English language journals]. Arch Bronconeumol 2002;38(12):574-9 http://dx.doi.org/10.1016/50300-2896(02)75293-9

22. Thomson Reuters. ISI Web of Knowledge Journal Impact Factors 2012. http://wok.mimas.ac.uk/ (accessed 15 August 2012).

23. Ntala C, Birmpili P, Worth A, Anderson NH, Sheikh A. The quality of reporting of randomised controlled trials in asthma: systematic review protocol. Prim Care Respir J 2013:22(1):PS1-PS8. http://dx.doi.org/10.4104/pcri.2013.00003

24. The World Bank Group 2012. http://data.worldbank.org/country/ (accessed 26
July 2012).

25. Higgins JPT GSe. Cochrane Handbook for Systematic Reviews of Interventions Version 5.1.0 [updated March 2011]. The Cochrane Collaboration, 2011. Available from: www.cochrane-handbook.org

26. Wilson E. Probable inference, the law of succession, and statistical inference. J Am Stat Assoc 1927;22(158):209-12. http://dx.doi.org/10.2307/2276774

27. Camm CF, Chen Y, Sunderland N, Nagendran M, Maruthappu M, Camm AJ. An assessment of the reporting quality of randomised controlled trials relating to antiarrhythmic agents (2002-2011). Int J Cardiol 2013;168(2):1393-6. http://dx.doi.org/10.1016/j.ijcard.2012.12.020

28. Hopewell S, Dutton S, Yu LM, Chan AW, Altman DG. The quality of reports of randomised trials in 2000 and 2006: comparative study of articles indexed in PubMed. BMJ 2010;340:c723. http://dx.doi.org/10.1136/bmj.c723

29. Farrokhyar F, Chu R, Whitlock R, Thabane L. A systematic review of the quality of publications reporting coronary artery bypass grafting (CABG) trials. Ann Epidemiol 2005;15(8):645. http://dx.doi.org/10.1016/j.annepidem.2005.06.042

30. Peron J, Pond GR, Gan HK, et al. Quality of reporting of modern randomized controlled trials in medical oncology: a systematic review. J Natl Cancer Inst 2012;104(13):982-9. http://dx.doi.org/10.1093/jnci/djs259

31. Bausch B, Spaar A, Kleijnen J, Puhan MA. Quality of randomised trials in COPD. Eur Respir J 2009;34(5):1060-5. http://dx.doi.org/10.1183/09031936.00159108

32. Glasziou $P$, Meats $E$, Heneghan $C$, Shepperd $S$. What is missing from descriptions of treatment in trials and reviews? BMJ 2008;336(7659):1472-4. http://dx.doi.org/10.1136/bmj.39590.732037.47

33. Ioannidis JP, Lau J. Completeness of safety reporting in randomized trials: an evaluation of 7 medical areas. JAMA 2001;285(4):437-43. http://dx.doi.org/10.1001/jama.285.4.437

34. Silagy CA, Middleton P, Hopewell S. Publishing protocols of systematic reviews: comparing what was done to what was planned. JAMA 2002;287(21):2831-4. http://dx.doi.org/10.1001/jama.287.21.2831

35. Krimsky S, Rothenberg LS. Financial interest and its disclosure in scientific publications. JAMA 1998;280(3):225-6. http://dx.doi.org/10.1001/jama.280.3.225

36. Devereaux PJ, Choi PT, El-Dika S, et al. An observational study found that authors of randomized controlled trials frequently use concealment of randomization and blinding, despite the failure to report these methods. J Clin Epidemiol 2004;57(12):1232-6. http://dx.doi.org/10.1016/j.jclinepi.2004.03.017

37. Pildal J, Chan AW, Hrobjartsson A, Forfang E, Altman DG, Gotzsche PC. Comparison of descriptions of allocation concealment in trial protocols and the published reports: cohort study. BMJ 2005;330(7499):1049. http://dx.doi.org/10.1136/bmj.38414.422650.8F

38. Soares HP, Daniels S, Kumar A, et al. Bad reporting does not mean bad methods for randomised trials: observational study of randomised controlled trials performed by the Radiation Therapy Oncology Group. BMJ 2004;328(7430):22-4. http://dx.doi.org/10.1136/bmj.328.7430.22

39. Toulmonde M, Bellera C, Mathoulin-Pelissier S, Debled M, Bui B, Italiano A. Quality of randomized controlled trials reporting in the treatment of sarcomas. J Clin Oncol 2011;29(9):1204-9. http://dx.doi.org/10.1200/JCO.2010.30.9369

40. Moher D, Pham B, Jones A, et al. Does quality of reports of randomised trials affect estimates of intervention efficacy reported in meta-analyses? Lancet 1998;352(9128):609-13. http://dx.doi.org/10.1016/S0140-6736(98)01085-X

41. Schulz KF, Chalmers I, Hayes RJ, Altman DG. Empirical evidence of bias. Dimensions of methodological quality associated with estimates of treatment effects in controlled trials. JAMA 1995;273(5):408-12. http://dx.doi.org/10.1001/jama.1995.03520290060030 
Appendix 1

1. Aubier $M$, Buhl R, Ekstrom $T$, et al. Comparison of two twice-daily doses of budesonide/formoterol maintenance and reliever therapy. Eur Respir $J$ 2010;36(3):524-30. http://dx.doi.org/10.1183/09031936.00022010

2. Baraket M, Oliver BGG, Burgess JK, Lim S, King GG, Black JL. Is low dose inhaled corticosteroid therapy as effective for inflammation and remodeling in asthma? A randomized, parallel group study. Respir Res 2012;13:11. http://dx.doi.org/10.1186/1465-9921-13-11

3. Bateman ED, Bleecker ER, Lotvall J, et al. Dose effect of once-daily fluticasone furoate in persistent asthma: a randomized trial. Respir Med 2012;106(5):642-50. http://dx.doi.org/10.1016/j.rmed.2012.01.004

4. Bodzenta-Lukaszyk A, Pulka G, Dymek A, et al. Efficacy and safety of fluticasone and formoterol in a single pressurized metered dose inhaler. Respir Med 2011;105(5):674-82. http://dx.doi.org/10.1016/..rmed.2010.11.011

5. Bruzzese J-M, Sheares BJ, Vincent EJ, et al. Effects of a school-based intervention for urban adolescents with asthma. A controlled trial. Am J Respir Crit Care Med 2011:183(8):998-1006. http://dx.doi.org/10.1164/rccm.201003-04290C

6. Busse WW, Morgan WJ, Gergen PJ, et al. Randomized trial of omalizumab (anti-lgE) for asthma in inner-city children. N Engl J Med 2011;364(11):1005-15. http://dx.doi.org/10.1056/NEJMoa1009705

7. Castro M, Mathur S, Hargreave F, et al. Reslizumab for poorly controlled, eosinophilic asthma: a randomized, placebo-controlled study. Am J Respir Crit Care Med 2011;184(10):1125-32. http://dx.doi.org/10.1164/rccm.201103-03960C

8. Castro $M$, Rubin AS, Laviolette $M$, et al. Effectiveness and safety of bronchial thermoplasty in the treatment of severe asthma: a multicenter, randomized, doubleblind, sham-controlled clinical trial. Am J Respir Crit Care Med 2010;181(2):11624. http://dx.doi.org/10.1164/rccm.200903-0354OC

9. Chanez P, Stallaert R, Reznikova E, Bloemen P, Adamek L, Joos G. Effect of salmeterol/fluticasone propionate combination on airway hyper-responsiveness in patients with well-controlled asthma. Respir Med 2010;104(8):1101-09. http://dx.doi.org/10.1016/..rmed.2010.04.001

10. Corren J, Lemanske RF, Hanania NA, et al. Lebrikizumab treatment in adults with asthma. N Engl J Med 2011;365(12):1088-98 http://dx.doi.org/10.1056/NEJMoa1 106469

11. Dahl R, Engelstatter R, Trebas-Pietras E, Kuna P. A 24-week comparison of low-dose ciclesonide and fluticasone propionate in mild to moderate asthma. Respir Med 2010;104(8):1121-30. http://dx.doi.org/10.1016/j.rmed.2010.03.032

12. Deschildre A, Beghin L, Salleron J, et al. Home telemonitoring (forced expiratory volume in $1 \mathrm{~s}$ ) in children with severe asthma does not reduce exacerbations. Eur Respir J 2012;39(2):290-6. http://dx.doi.org/10.1183/09031936.00185310

13. Djukanovic R, Wilson SJ, Moore WC, et al. Montelukast added to fluticasone propionate does not alter inflammation or outcomes. Respir Med 2010;104(10):1425-35. http://dx.doi.org/10.1016/j.rmed.2010.04.004

14. Ducharme FM, Zemek RL, Chalut D, et al. Written action plan in pediatric emergency room improves asthma prescribing, adherence, and control. Am J Respir Crit Care Med 2011;183(2):195-203. http://dx.doi.org/10.1164/rccm.201001-01150C

15. Fleming L, Wilson N, Regamey N, Bush A. Use of sputum eosinophil counts to guide management in children with severe asthma. Thorax 2012;67(3):193-8. http://dx.doi.org/10.1136/thx.2010.156836

16. Gallegos-Solorzano MC, Perez-Padilla R, Hernandez-Zenteno RJ. Usefulness of inhaled magnesium sulfate in the coadjuvant management of severe asthma crisis in an emergency department. Pulm Pharmacol Ther 2010;23(5):432-7. http://dx.doi.org/10.1016/..pupt.2010.04.006

17. Hanania NA, Alpan $\mathrm{O}$, Hamilos DL, et al. Omalizumab in severe allergic asthma inadequately controlled with standard therapy: a randomized trial. [Summary for patients in Ann Intern Med 2011 May 3;154(9):I28; PMID: 21536934]. Annals of Inter Med 2011;154(9):573-82.

http://dx.doi.org/10.7326/0003-4819-154-9-201105030-00002

18. Hashimoto $S$, Brinke AT, Roldaan AC, et al. Internet-based tapering of oral corticosteroids in severe asthma: a pragmatic randomised controlled trial. Thorax 2011;66(6):514-20. http://dx.doi.org/10.1136/thx.2010.153411

19. Writing Committee for the American Lung Association Asthma Clinical Research C,
Holbrook JT, Wise RA, et al. Lansoprazole for children with poorly controlled asthma: a randomized controlled trial. JAMA 2012;307(4):373-81. http://dx.doi.org/ 10.1001/jama.2011.2035

20. Hozawa S, Terada M, Hozawa M. Comparison of budesonide/formoterol Turbuhaler with fluticasone/salmeterol Diskus for treatment effects on small airway impairment and airway inflammation in patients with asthma. Pul Pharmacol Ther 2011;24(5):571-6. http://dx. doi.org/10.1016/j.pupt.2011.05.004

21. Janson SL, McGrath KW, Covington JK, Baron RB, Lazarus SC. Objective airway monitoring improves asthma control in the cold and flu season: a cluster randomized trial. Chest 2010;138(5):1148-55. http://dx.doi.org/10.1378/chest.09-2394

22. Kurashima K, Kagiyama N, Takayanagi N, Sugita $Y$. Comparison of high-dose salmeterol/fluticasone and moderate-dose salmeterol/fluticasone plus low-dose mometasone in patients with severe persistent asthma. Respirology 2011;16(5):784-9. http://dx.doi.org/10.1111/j.1440-1843.2011.01967.x

23. Lipworth BJ, Short PM, Williamson PA, Clearie KL, Fardon TC, Jackson CM. A randomized primary care trial of steroid titration against mannitol in persistent asthma: STAMINA trial. Chest 2012;141(3):607-15. http://dx.doi.org/10.1378/chest.11-1748

24. Meltzer EO, Kuna P, Nolte H, Nayak AS, Laforce C, Investigators PS. Mometasone furoate/formoterol reduces asthma deteriorations and improves lung function. Eur Respir J 2012;39(2):279-89. http://dx.doi.org/10.1183/ 09031936.00020310

25. Mendes FAR, Goncalves RC, Nunes MPT, et al. Effects of aerobic training on psychosocial morbidity and symptoms in patients with asthma: a randomized clinical trial. Chest 2010;138(2):331-7. http://dx.doi.org/10.1378/chest.09-2389

26. Oei SM, Thien FCK, Schattner RL, et al. Effect of spirometry and medical review on asthma control in patients in general practice: a randomized controlled trial. Respirology 2011;16(5):803-10 http://dx.doi.org/10.1111/j.1440-1843.2011.01969.x

27. Pedersen S, Potter P, Dachev $S$, et al. Efficacy and safety of three ciclesonide doses vs placebo in children with asthma: the RAINBOW study. Respir Med 2010;104(11):1618-28. http://dx.doi.org/10.1016/j.rmed.2010.06.012

28. Postma DS, O'Byrne PM, Pedersen S. Comparison of the effect of low-dose ciclesonide and fixed-dose fluticasone propionate and salmeterol combination on long-term asthma control. Chest 2011;139(2):311-18. http://dx. doi.org/10.1378/chest.09-1735

29. Powell H, Murphy VE, Taylor DR, et al. Management of asthma in pregnancy guided by measurement of fraction of exhaled nitric oxide: a double-blind, randomised controlled trial. Lancet 2011;378(9795):983-90. http://dx.doi.org/10.1016/501406736(11)60971-9

30. Price D, Musgrave SD, Shepstone L, et al. Leukotriene antagonists as first-line or addon asthma-controller therapy. N Engl J Med 2011;364(18):1695-707. http://dx.doi.org/10.1056/NEJMoa1010846

31. Reddel HK, Gibson PG, Peters MJ, et al. Down-titration from high-dose combination therapy in asthma: Removal of long-acting beta(2)-agonist. Respir Med 2010;104(8):1110-20. http://dx.doi.org/10.1016/j.rmed.2010.04.003

32. Renzi PM, Howard LA, Ortega HG, Ahmad FF, Chapman KR. Low-dose fluticasone propionate with and without salmeterol in steroid-naive patients with mild, uncontrolled asthma. Respir Med 2010;104(4):510-17. http://dx.doi.org/10.1016/..rmed.2009.10.025

33. Vaessen-Verberne AAPH, van den Berg NJ, van Nierop JC, et al. Combination therapy salmeterol/fluticasone versus doubling dose of fluticasone in children with asthma. Am J Respir Crit Care Med 2010; 182(10):1221-7. http://dx.doi.org/10.1164/rccm.201002-01930C

34. Wilson SR, Farber HJ, Knowles SB, Lavori PW. A randomized trial of parental behavioral counseling and cotinine feedback for lowering environmental tobacco smoke exposure in children with asthma: results of the LET'S Manage Asthma trial. Chest 2011;139(3):581-90. http://dx.doi.org/10.1378/chest.10-0772

35. Wilson SR, Strub P, Buist AS, et al. Shared treatment decision making improves adherence and outcomes in poorly controlled asthma. Am J Respir Crit Care Med 2010;181(6):566-77. http://dx.doi.org/ 10.1164/rccm.200906-09070C 